\title{
Viscosimetric determination of cellulase activity: critical analyses
}

\author{
Roland Guignard and Paul-Emile Pilet
}

Institute of Plant Biology and Physiology, University of Lausanne, 1005 Lausanne, Pl. de la Riponne, Switzerland

\begin{abstract}
The mode of expression of cellulase activity obtained by viscosimetric measurement is analysed. After testing different types of substrates, it appears that the best one is hydroxyethylcellulose used at a high degree of polymerisation and a high concentration. Comparison of results obtained with cellulases from Trichoderma viride and extracted from Pisum sativum favours the validity of the determination proposed. Possible physiological significance of the measurements of cellulase activity is also discussed.
\end{abstract}

Cellulases seem to be implicated in phenomena such as abscission (18), ripening (17), cell differentiation (21), and cell expansion (6). On the other hand, their activities are controlled by some plant hormones $(3,8,18,24)$. At first, some simple relationships between cellulase and growth were proposed (16), but the participation of cellulases in such a process - if controlled by certain enzymes $(7,30)$ - still remains questionable. The exogenous application of cellulases changed the extensibility of the cell wall (20), but failed to stimulate growth $(20,25)$. It seems difficult to generalize observations $(19)$ for which the physiological significance has yet to be fully investigated. The occurence and the analysis of endogenous cellulases in a growing system have still to be demonstrated. Technical questions seem to be of prime importance to solve these problems.

Several techniques for measuring cellulase activity have been proposed, and the viscosimetric method seems to be the most sensitive (27). However it brings certain problems such as: the choice of substrate, the expression of enzyme activity, the distinction between enzyme and polymer properties, etc. The usual substrate is the carboxymethylcellulose (CMC), but it seems that the non-ionic substrate hydroxyethylcellulose (HEC) - subject to extensive studies $(28,29)$ - can be considered the best substrate to test cellulase activity $(4,5,11)$. If standard units of cellulase are to be discussed, because of the present nonstandardization of substrates ( 1 ), the choice of units remains essential to express enzyme activity.

The aim of the present paper is to select the best substrate for a viscosimetric

Abbreviations: CMC, carboxymethylcellulose; HEC, hydroxyethylcellulose; DP, degree of polymerisation; cst, centistoke; CE, cellulase extracted from Pisum sativum; CO, cellulase Onozuka R-10. 
Table 1 Characteristics of the substrates used to analyse the cellulase activity

\begin{tabular}{rcc}
\hline \multicolumn{1}{c}{ Substrate } & $\mathrm{DP}_{\mathrm{w}}{ }^{a}$ & $\mathrm{DP}_{\mathrm{w}}{ }^{b}$ \\
\hline HEC $250 \mathrm{H}$ & 3400 & 3160 \\
$250 \mathrm{M}$ & 2500 & 2200 \\
$250 \mathrm{~K}$ & 1700 & 1690 \\
$250 \mathrm{G}$ & 800 & 986 \\
$250 \mathrm{~L}$ & 300 & 328 \\
CMC 7M8SF & 1100 & 1296 \\
\hline
\end{tabular}

For HEC: moles of substituent combined M.S. $=2.5$ (noted 250);

For CMC: degree of substitution D.S. $=0.7$.

$\mathrm{DP}_{\mathrm{w}}$ : average degree of polymerisation (weight average)

- Approximate values according to Hercules.

$b$ Values determined from Table 2 and by use of the equations:

$[\eta]=10^{-2} \times \mathrm{DP}_{\mathrm{w}}{ }^{0.87}$ (Hercules data), for $\mathrm{CMC}:[\eta]_{0.1 \mathrm{~N} \mathrm{NaCl}}=1.8 \times 10^{-2} \times \mathrm{DP}_{\mathrm{w}} 0.79(28)$ with $[\eta]=$ 5.18 .

analysis, by comparing the results obtained with commercial cellulase and cellulase prepared from Pisum sativum $(3,16)$, using HEC and CMC as substrate. Expression of cellulase activity and its significance will be discussed.

\section{Materials and methods}

Pisum sativum L. var. Alaska were grown (dark, $25^{\circ} \mathrm{C}$ ) for about three days on vermiculite. The first $\mathrm{cm}$ (plumule+hook) of the first internode was used. This segment induced a drop in viscosity similar to that of the third internode usually employed. From these first internodes, $60 \mathrm{~g}$ were homogenized in a blendor in $50 \mathrm{ml}$ of $10^{-2} \mathrm{M}$ phosphate buffer $\mathrm{pH} 6$. The homogenate was centrifuged $(25000 \times \mathrm{g}, 15 \mathrm{~min})$; the clear supernatant was frozen with liquid nitrogen, then lyophilised, and $1.5 \mathrm{~g}$ of powder was obtained. An aliquot was dissolved in water just prior to the assay.

Commercial cellulase Onozuka R-10 (source: Trichoderma viride) was purchased from Kinki Yakult Co., Nishinomiya. It must be noted that this preparation contained some hemicellulases.

The characteristics of the substrates CMC and HEC - generous gift from Hercules Powder Co. - are presented in Table 1. The HEC and CMC solutions were prepared in phosphate buffer one to three days before use, and kept at $4^{\circ} \mathrm{C}$.

Enzyme and substrate solutions were thoroughly mixed (1/1) and charged into a Cannon-Manning semi-micro viscometer calibrated, size 200. Measurements were performed at $35 \pm 0.01^{\circ} \mathrm{C}$ every $10 \mathrm{~min}$ for $1 \mathrm{hr}$, with an efflux time greater than $100 \mathrm{sec}$; the viscosity $(\nu)$ of the solvent was 0.74 cst. For all the assays, blanks were prepared by heat inactivation of the enzyme solution ( $1 \mathrm{hr}$, $100^{\circ} \mathrm{C}$ ); if not mentioned, the drop in viscosity was negligible.

\section{Results and discussion}

Cellulase action on the viscosity of an HEC solution is presented in Fig. 1A. The curves obtained show a non-linear relation to time. This can be ruled out 


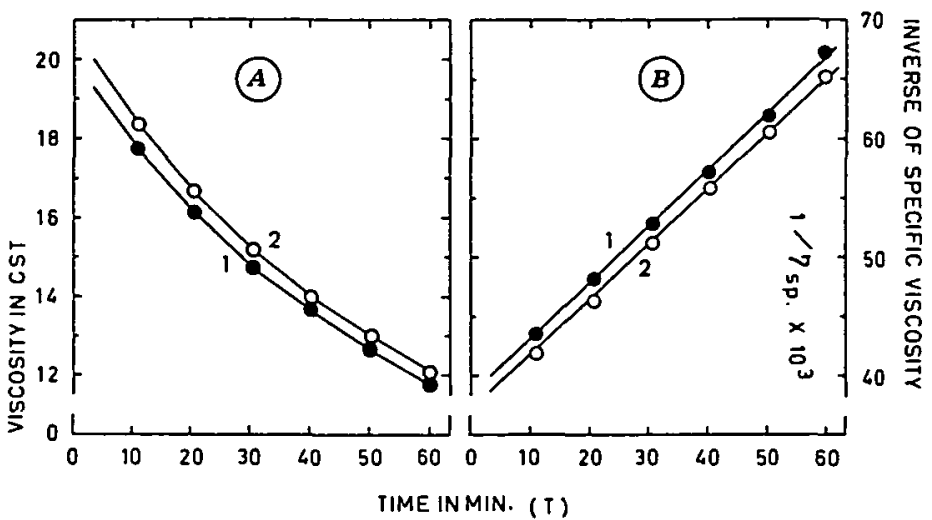

Fig. 1. Cellulase activity. (A) Drop in viscosity $(\nu)$ as a function of incubation time. Substrate HEC $250 \mathrm{H}$. Final concentration $0.35 \%$. CO: $0.125 \mu \mathrm{g} / \mathrm{ml}$ (1); CE: $5 \mathrm{mg} / \mathrm{ml}$ (2). Reaction time ( $T$ ) is obtained from the equation: $T=T_{0}+t / 2$ with $T_{0}$ : starting time of measurement with efflux time t. The initial values can be extrapolated from results shown in $B$. (B) Change in the inverse of specific viscosity $(1 / \eta \mathrm{sp})$ in relation to time.

by plotting the inverse of specific viscosity $(1 / \eta \mathrm{sp})$ as a function of time (Fig. 1B) - as was earlier proposed (15) - with:

$$
\eta_{\mathrm{sp}}=\left(\nu_{\text {solution }} / \nu_{\text {solvent }}\right)-1
$$

The difference in density between solution and solvent was found to be negligible.

What is the significance of such results? Is the non-linearity a consequence of enzyme activity or is it a viscosimetric property of polymers in solution? Which function could be used to express the enzyme activity and what is its best formulation? It seems that the last question must be solved before drawing conclusion about cellulase activity from viscosimetric measurements.

The standard unit of cellulase corresponds to the quantity of enzyme which hydrolyses one microequivalent of glycoside bonds per min (initial rate of reaction) under experimental conditions. Thus enzyme activity would be $(10)$ :

$$
A=10^{6} \times P \times\left[\frac{d}{d t} \frac{1}{M_{n}}\right]_{t=0}
$$

Table 2 Slope $(a)$ and intrinsic viscosity $([\eta])$ for different substrates

\begin{tabular}{rcc}
\hline \multicolumn{1}{c}{ Substrate } & $a$ & {$[\eta]$} \\
\hline HEC $250 \mathrm{H}$ & 2.55 & 11.05 \\
$250 \mathrm{M}$ & 1.89 & 8.05 \\
$250 \mathrm{~K}$ & 1.23 & 6.41 \\
$250 \mathrm{G}$ & 0.64 & 4.01 \\
$250 \mathrm{~L}$ & 0.20 & 1.54 \\
\hline
\end{tabular}

Values using the regression line of the function: $\log \frac{\eta \mathrm{sp}}{\mathrm{c}}=\log [\eta]+a \times \mathrm{c}$.

Measurements at $35^{\circ} \mathrm{C}$; the determinations of $[\eta]$ at $25^{\circ} \mathrm{C}$ were not significantly different, from [ $\eta$ ] at $35^{\circ} \mathrm{C}$, under the present experimental conditions. 


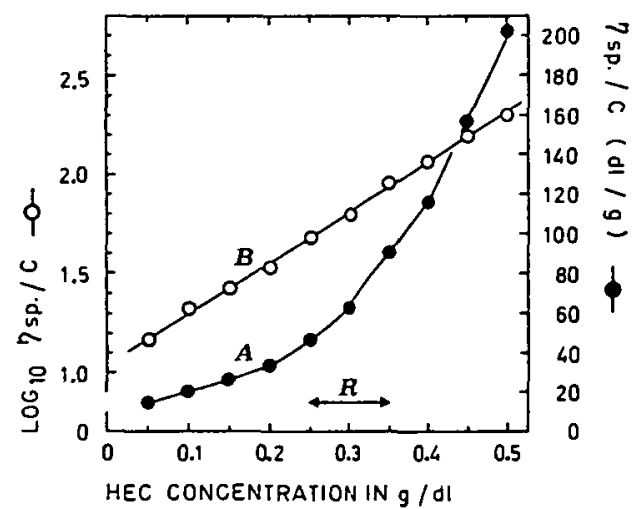

Fig. 2.

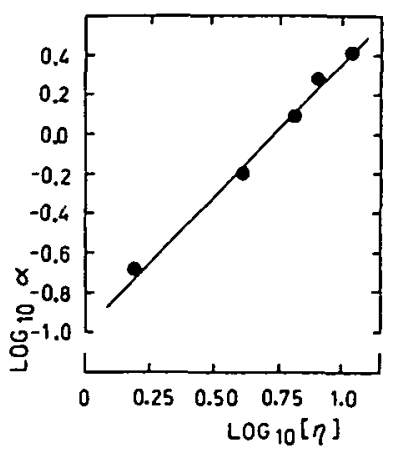

Fig. 3.

Fig. 2. Verification of the Huggins relation and its linearisation for $H E C 250 \mathrm{H}$. (A) In the usual range of measurement ( $R$ ) the Huggins relation (equation 5) cannot be used. (B) Linearisation of the function depicted in $\mathrm{A}$ by plotting $\log \frac{\eta \mathrm{sp}}{\mathrm{c}}$ as a function of the concentration.

Fig. 3. Relation between the slope $\alpha$ and the intrinsic viscosity [ $\eta$ ] (see Table 2). The equation of this relation is $\log \alpha=\beta \log [\eta]+\mu$ with: $\beta=1.31$ and $\mu=-0.95$.

A: number of microequivalents of glycoside bonds hydrolysed per unit of time under experimental conditions; $P$ : weight of polymer per assay; $M_{n}$ : number average molecular weight.

The relationship between $M_{n}$ and the viscosity measurement is certainly complex, but it can be formulated:

$$
\mathrm{M}_{\mathrm{v}}=k \times \mathrm{M}_{\mathrm{n}}
$$

$M_{v}$ : viscosity average molecular weight which, in our case, can be considered as a weight average molecular weight $(29) ; k$ : ratio between average molecular weight and number average molecular weight.

$\mathrm{M}_{\mathbf{v}}$ is related to the intrinsic viscosity $([\eta])$ according to the modified Staudinger equation:

$$
[\eta]=\mathrm{H} \times \mathrm{M}_{\mathbf{v}} x
$$

$\mathrm{H}$ and $\boldsymbol{x}$ being empirical coefficients.

$[\eta]$ can be expressed in terms of viscosity of the dilute solution of polymer (Huggins equation):

$$
\frac{\eta_{\mathrm{sp}}}{\mathrm{c}}=[\eta]+\mathrm{K} \times[\eta]^{2} \times \mathrm{c}
$$

c: polymer concentration in $\mathrm{g} / \mathrm{dl}, \mathrm{K}$ : Huggins constant.

From this, under suitable experimental conditions, Hulme (10) proposed:

$$
\mathrm{M}_{\mathrm{n}}=\mathrm{S} \times \eta_{\mathrm{sp}}
$$

But this relation, which is linear, is only good - according to Hulme (10) 

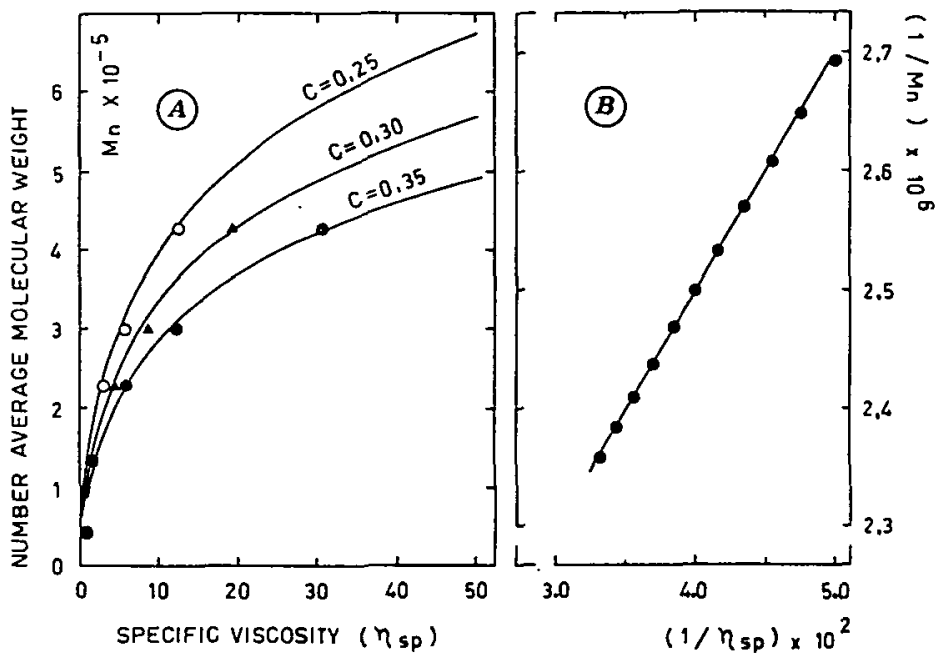

Fig. 4. Variation of the number of molecular weight $M_{n}$ or $1 / M_{n}$ in relation to specific viscosity $\eta$ sp or $1 / \eta s p$. (A) For different values of concentration (c), calculation from equations 9, 10 was done using an ordinator programme. Experimental values were obtained from measurement of specific viscosity for different HEC solutions at several concentrations. (B) Linearisation of the relation $1 / \mathbf{M}_{\mathbf{n}}=\mathfrak{f}(1 / \eta$ sp). Range $20 \leq \eta \mathrm{sp} \leq 30, c=0.35 \%$.

- for a dilute solution of substrate, with a small drop in viscosity as a function of time. As discussed later on, these conditions are not the best ones for physiological purposes. Consequently it would be of interest to test the above mentioned relationship (6) for higher concentrations.

Under the present experimental conditions, the Huggins relation was not verified (Fig. 2A). But for concentrated solutions of polymer, the following relation can be proposed (Fig. 2B):

$$
\log \frac{\eta_{\mathrm{sp}}}{\mathrm{c}}=\log [\eta]+\alpha \times c
$$

The coefficient $\alpha$ itself is related to $[\eta]$; this function can be characterised by using different types of HEC (Table 2) and by plotting these results on a graph with douible logarithmic scale (Fig. 3). Thus it can be written:

$$
\log \alpha=\beta \times \log [\eta]+\mu
$$

$\beta=1.31$ and $\mu=-0.95$

By incorporating (8) in (7), the following equation can be obtained. It allows a determination of $[\eta]$ from a one point measurement of viscosity:

$$
\log \frac{\eta_{\mathrm{sp}}}{\mathrm{c}}=\log [\eta]+\mathrm{c} \times 10^{\beta \times \log [\eta]+\mu}
$$

Using relationships (3) and (4), it can be noticed that:

$$
\mathrm{M}_{\mathrm{n}}=\frac{1}{k} \times\left[\frac{[\eta]}{\mathrm{H}}\right]^{1 / x}
$$




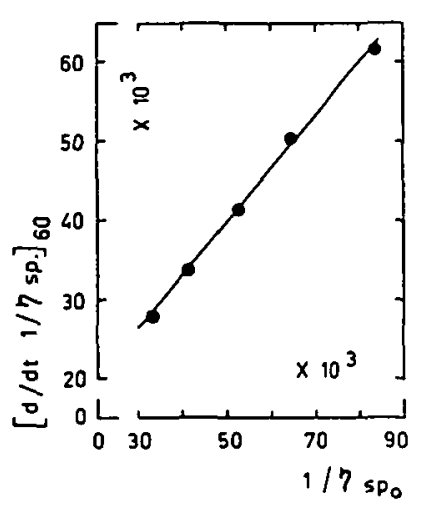

Fig. 5.

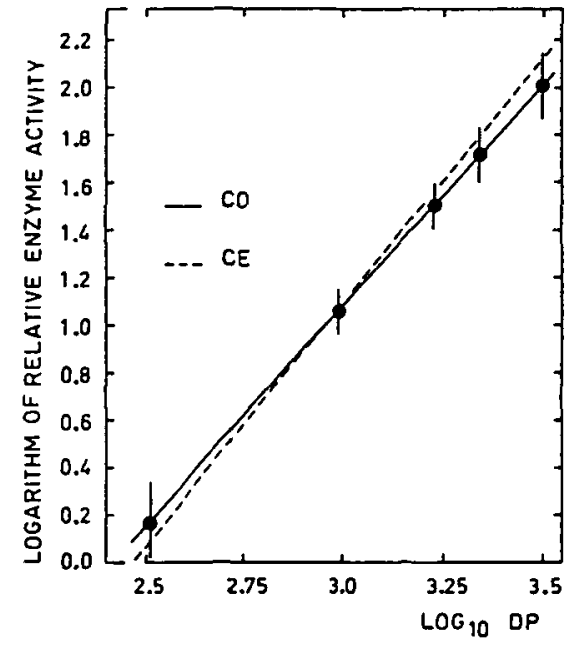

Fig. 6.

Fig. 5. Variation of the inverse of specific viscosity ( $1 / \eta \mathrm{sp}$ ) for $60 \mathrm{~min}$ of incubation in relation to the inverse of specific viscosity at zero time $\left(1 / \eta s p_{0}\right)$. Enzyme: CO: $125 \mu \mathrm{g} / \mathrm{ml}$. Substrate: HEC $250 \mathrm{H}$. The values of $\left[\frac{\mathrm{d}}{\mathrm{dt}} \frac{1}{\eta \mathrm{sp}}\right]_{60}$ and $1 / \eta \mathrm{sp}_{0}$ are obtained by linear regression of the function $1 / \eta \mathrm{sp}=$ $f(t)$.

Fig. 6. Relative enzyme activity as a function of the degree of polymerisation (DP). See Tables 1 and 4. Standard errors are indicated. The difference between CO and CE is without significance.

$\mathrm{H}=7.6 \times 10^{-5} ; x=0.87 ; k=2$, which can be considered constant in the initial time of the enzyme reaction and for the different types of polymers (29).

The function $M_{n}=f\left(\eta_{\mathbf{s p}}\right)$ can be plotted for different values of $\mathrm{c}$ (Fig. 4A). The experimental values of $\eta \mathrm{sp}$, for different types of HEC and for a few chosen concentrations, fit the calculated curves well. From this figure it can be seen that:

1) For the usual range of analyses $\left(20 \leq \eta_{\mathrm{sp}} \leq 30\right)$ the relationship between $M_{n}$ and $\eta$ sp could be considered as a linear form which differs from equation (6) by an origine ordinate. But the relationship (ll) $1 / M_{n}=S^{\prime} \times\left(1 / \eta_{s p}\right)+B$ (Fig.

\section{Table 3 Reproducibility of enzyme activity}

\begin{tabular}{crrrrr}
\hline $\begin{array}{c}\text { Enzyme } \\
\text { activity }\end{array}$ & \multicolumn{5}{c}{ Experiment } \\
\cline { 2 - 6 } & \multicolumn{1}{c}{1} & \multicolumn{1}{c}{3} & \multicolumn{1}{c}{4} & \multicolumn{1}{c}{5} \\
\hline $\begin{array}{c}\text { a } \times 10^{3} \\
\pm \delta\end{array}$ & 29.06 & 30.37 & 28.16 & 29.47 & 28.94 \\
Average $^{a}$ & 0.80 & 0.28 & 0.46 & 0.35 & 0.95 \\
& & & $29.19 \pm 1.01$ & & \\
\hline
\end{tabular}

Substrate HEC $250 \mathrm{H}$ final concentration $0.35 \%$.

Enzyme: cellulase Onozuka-R-10: $0.125 \mu \mathrm{g} / \mathrm{ml}$.

a The mean value with the confident interval is given $(P=0.05)$. 
Table 4 Relative enzyme activity for different substrates

\begin{tabular}{rccc}
\hline Substrate & $\begin{array}{c}\text { Concentration } \\
(\%)\end{array}$ & \multicolumn{2}{c}{ Relative enzyme activity $\%$} \\
\cline { 3 - 4 } HEC $250 \mathrm{H}$ & 0.35 & 100 & $\mathrm{CE}$ \\
$250 \mathrm{M}$ & 0.40 & 73.6 & 100 \\
$250 \mathrm{~K}$ & 0.65 & 28.0 & 82.0 \\
$250 \mathrm{G}$ & 1.00 & 9.8 & 36.6 \\
$250 \mathrm{~L}$ & 3.00 & 1.8 & 11.9 \\
CMC 7M8SF & 0.90 & 9.2 & 1.1 \\
\hline
\end{tabular}

Average values for two or three assays, expression in percentage (\%) of the HEC $250 \mathrm{H}$ value; for measurements with CMC, blank values were substracted; data with CMC 7 HF and CMC 7 LF are not given because of technical problems with dissolving these substrates.

4B) was obtained for a similar region of determination. This may justify the use of $1 / \eta_{\mathbf{s p}}$ for enzyme activity determination.

2) Since the relationship $M_{n}=f\left(\eta_{s p}\right)$ depends upon the concentration, it would be interesting to study the variation of $1 / \eta \mathrm{sp}$, for a $60 \mathrm{~min}$ enzyme incubation, as a function of the inverse of substrate concentration directly expressed with its initial specific viscosity $1 / \eta \mathrm{sp}_{0}$ (Fig. 5). Such a function is almost linear. Then it is necessary to standardize the value of the activity, considering $S^{\prime}$ as constant and comparing several results:

$$
\mathrm{a}=60 \times 50 \times 10^{-3} \times \frac{\mathrm{d}}{\mathrm{dt}} \frac{\mathrm{l} / \eta_{\mathrm{sp}}}{1 / \eta_{\mathrm{spo}}}
$$

a: variation of $1 / \eta_{\mathrm{sp}}$, at $35^{\circ} \mathrm{C}$, for an initial value of $1 / \eta_{\mathrm{sp} 0}=50 \times 10^{-3}$ and a $60 \mathrm{~min}$ incubation time (arbitrarily chosen). Such an activity is obtained when using a computer programme which gives directly the confident interval $\delta$ ( $P$ : 0.05$)$ due to the slope and the origine ordinate fluctuations of the linear regression of $1 / \eta_{\mathrm{Bp}}=\mathrm{f}(\mathrm{t})$. The reproducibility of the method is indicated in Table 3 .

It is now of interest to select the best substrate to be used for viscosimetric measurements of cellulase. The types of substrates are given in Table 1. They

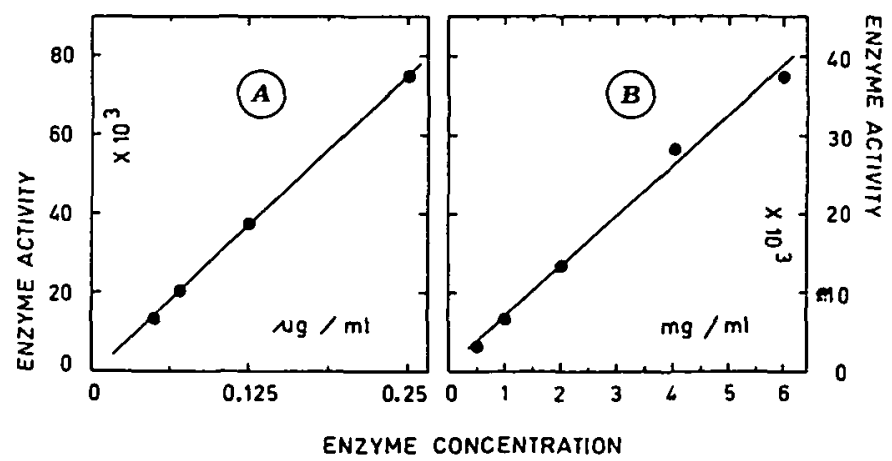

Fig. 7. Enzyme activity and concentration. Substrate HEC $250 \mathrm{H}$; final concentration $0.35 \%$. A: cellulase Onozuka R-10; B: cellulase extracted from Pisum. 
are employed for both types of enzymes (Table 4). The results presented on a graph with double logarithmic scales (Fig. 6) lead to several comments. 1) HEC $250 \mathrm{H}$ is certainly the best substrate. This does not mean that the differences observed among the several types of substrates is due to different enzyme action, but results from viscosimetric properties of polymers. It is clear that $\mathrm{S}^{\prime}$ - which depends on $\mathrm{c}-$ is not the same, and the activity measured is related to it. The relationship between the slope $S^{\prime}$ and the concentration can be determined from equations (9) and (10). Then it is possible to draw a conclusion about the enzyme activity $A(2)$ as a function of the degree of polymerisation. From calculated data (not presented here) it can be said that enzymes show no specificity towards polymer length in the range of DP tested. 2) There is a close similarity between the results obtained for the two types of enzymes. 3) The data given by CMC 7M8SF are very similar to those obtained with HEC of almost the same DP.

The validity of the present method is illustrated in Fig. 7 ; the activity of the enzyme, as a function of its concentration, is expressed for both systems.

\section{Conclusions}

Analyses of the mode of expressing cellulase activity and its significance have been presented. It must be noted first that the non-linearity of the decrease in viscosity of HEC solution due to enzyme action is not necessarily related to the enzyme properties but depends upon polymer characteristics. It is preferable to use a relatively concentrated solution of polymer with a high DP value for physiological experiments based on a very low level of cellulases. The relatively high initial viscosity and change of rate of shear do not interfere with the dosage under the present experimental conditions (26). CMC tested seems to have no advantages. The close correspondence between results obtained with cellulase Onozuka and cellulase extracted from Pisum confirms the last analysis. The method of viscosimetric determination of cellulases is very sensitive when compared to the method of reducing groups (paper in preparation). Preliminary studies indicate that the best substrate for viscosimetric measurements is not necessarily the best one for the reducing groups analyses. But it must be noticed that the two techniques do not necessarily measure a similar enzyme system, since viscosimetric determination essentially concerns an endocellulase.

When using CMC or HEC as cellulase substrates, careful discussion of the results is necessary. As clearly indicated by its common name, cellulase has to hydrolyse cellulose: the enzyme system hydrolysing HEC or CMC is in fact a HECase or CMCase. Such a statement is important because a true cellulase can be free of CMCase $(2,9)$ or a CMCase can act as a xylanase, then as a hemicellulase (22). This indicates that the results obtained with CMC or HEC must not only be necessarily related to the physiological concept of cellulose, but also to hemicellulose, etc. Moreover, xyloglucan - perhaps a "key" compound of plant cell walls, when explaining cell extension - has a chemical structure similar to that of $\operatorname{HEC}(12,14)$ and it can be hydrolysed by a cellulase mixture $(13,23)$. Consequently, when using HEC to test cellulase activity, it would be difficult to conclude simply that this system does not possibly include a xyloglucanase which seems to be an essential enzyme for controlling growth. 


\section{References}

(1) Almin, K. E. and K. E. Eriksson: Influence of carboxymethylcellulose properties on the determination of cellulase activity in absolute terms. Arch. Biochem. Biophys. 124: 129-134 (1968).

( 2 ) Berghem, L. E. R., L. G. Pettersson and U. B. Axiö-Fredriksson: The mechanism of enzyme cellulose degradation, characterization and enzymatic properties of a $\beta$-1,4-glucan cellobiohydrolase from Trichoderma viride. Eur. J. Biochem. 53: 55-62 (1975).

(3) Byrne, H., N. V. Christou, D. P. S. Verma and G. A. Maclachlan: Purification and characterization of two cellulases from auxin-treated pea epicotyls. J. Biol. Chem. 250: 10121018 (1975).

(4) Child, J. J., D. E. Eveleigh and A. S. Sieben: Determination of cellulase activity using hydroxyethylcellulose as substrate. Can. J. Biochem. 51: 39-43 (1973).

(5) Courtois, J. E. et Bui Khac Diep: Recherches sur le dosage de cellulases et hemicellulases dans les préparations pharmaceutiques. IV Emploi de l'hydroxyethylcellulose comme substrat. Ann. Pharm. Fr. 25: 181-196 (1967).

(6) Datko, A. H. and G. A. Maclachlan: Indoleacetic acid and the synthesis of glucanases and pectic enzymes. Plant Physiol. 43: 735-742 (1968).

(7) Evans, M. L.: Rapid responses to plant hormones. Ann. Rev. Plant Physiol. 25: 195-223 (1974).

( 8 ) Ferrari, T. E. and P. G. Arnison: Extraction and partial characterization of cellulases from expanding pea epicotyls. Plant Physiol. 54: 487-493 (1974).

(9) Halliwell, G. and M. Griffin: The nature and mode of action of the cellulolytic component $\mathrm{C}_{1}$ of Trichoderma koningii on native cellulose. Biochem. J. 135: 587-594 (1973).

(10) Hulme, M. A.: Viscosimetric determination of carboxymethylcellulase in standard international units. Arch. Biochem. Biophys. 147: 49-54 (1971).

(11) Iwasaki, T., K. Tokuyasu and M. Funatsu: Determination of cellulase activity employing glycol cellulose as a substrate. J. Biochem. (Tokyo) 55: 30-36 (1964).

(12) Keegstra, K., K. W. Talmadge, W. D. Bauer and P. Albersheim: The structure of plant cell walls. III A model of the walls of suspension-cultured sycamore cells based on the interconnections of the macromolecular components. Plant Physiol. 51 : 188-196 (1973).

(13) Kooiman, P.: The constitution of Tamarindus-amyloide. Rec. Trav. Chim. Pays-Bas. 80: 849865 (1961).

(14) Labavitch, J. M. and P. M. Ray: Relationship between promotion of xyloglucan metabolism and induction of elongation by indole acetic acid. Plant Physiol. 54: 499-502 (1974).

(15) Levinson, H.S. and E. T. Reese: Enzymatic hydrolysis of soluble cellulose derivatives as measured by change of viscosity. J. Gen. Physiol. 33: 601-628 (1950).

(16) Maclachlan, G. A. and J. Perrault: Cellulase from pea epicotyls. Nature 204: 81-82 (1964).

(17) Pharr, D. M. and D. B. Dickinson: Partial characterization of $C_{\mathbf{x}}$ cellulase and cellobiase from ripening tomato fruits. Plant Physiol. $51: 577-583$ (1973).

(18) Reid, P. D., H. G. Strong, F. Lew and L. N. Lewis: Cellulase and abscission in the red kidney bean (Phaseolus vulgaris). Plant Physiol. 53: $732-737$ (1974).

(19) Roggen, H. P. J. R. and R. G. Stanley: Cell-wall hydrolysing enzymes in wall formation as measured by pollen-tube extension. Planta 84: 295-303 (1969).

(20) Ruesink, A. W.: Polysaccharidases and the control of cell wall elongation. ibid. 89: 95-107 (1969).

(21) Sheldrake, A. R.: Cellulase and cell differenciation in Acer pseudoplatinus. ibid. 95: 167-178 (1970).

(22) Toda, S., H. Suzuki and K. Nisizawa: Some enzymic properties and the substrate specificities of Trichoderma cellulases with special reference to their activity toward xylan. J. Ferment. Technol. 49: 499-521 (1971).

(23) Valent, B. S. and P. Albersheim: The structure of plant cell walls. V On the binding of xyloglucan to cellulose fibers. Plant Physiol. 54: 105-108 (1974). 
(24) Verma, D. P. S., G. A. Maclachlan, H. Byrne and D. Ewings: Regulation and in vitro translation of messenger ribonucleic acid for cellulase from auxin-treated pea epicotyls. J. Biol. Chem. 250: 1019-1026 (1975).

(25) Wada, S., E. Tanimoto and Y. Masuda: Cell elongation and metabolic turnover of the cell wall as affected by auxin and cell wall degrading enzymes. Plant $\&$ Cell Physiol. 9: 369-376 (1968).

(26) Van Wazer, J. R., J. W. Lyons, K. Y. Kim and R. E. Colwell: Viscosity and flow measurement. Ed. J. Wiley \& Sons (1963).

(27) Whitaker, D. R.: Cellulases. In The Enzymes. Ed. P. D. Boyer 3eme Edit. Vol. 5: 273-290 (1971), Academic Press, Inc.

(28) Wirick, M. G.: A study of the enzymic degradation of CMC and other cellulose ethers. $J$. Polymer. Sci. Part A-1, 6: 1965-1974 (1968).

(29) Wirick, M. G.: Study of the substitution pattern of hydroxyethylcellulose and its relationship to enzymic degradation. ibid. Part A-1, 6: 1705-1718 (1968).

(30) Yamagata, Y., R. Yamamoto and Y. Masuda: Auxin and hydrogen ion actions on light-grown pea epicotyl segments. II Effect of hydrogen ions on extension of the isolated epidermis. Plant E3 Cell Physiol, 15: 833-841 (1974). 